\title{
EEN DRIEHOEKSVERHOUDING IN DE AUTOMATISERING
}

\author{
door Dr. Th. J. Steenbergen
}

\section{Inleiding}

De snelle groei van het bedrijfsleven in de naoorlogse jaren heeft de taak van de leiding van het bedrijf aanmerkelijk verzwaard. Mede daardoor niet in staat om voldoende kennis op te doen van de ontwikkeling van nieuwe inzichten en technieken die betrekking hebben op de beïnvloeding van het bedrijfsgebeuren ter verkrijging van optimale resultaten, ontstond bij de leiding een behoefte aan bijstand.

Aan deze behoefte aan bijstand wordt enerzijds voldaan door de ter assistentie van de leiding aangestelde staffunktionarissen en, anderzijds, door het gebruikmaken van de diensten van externe differentiaties, zoals: het raadgevend bureau voor bedrijfsorganisatie, het ingenieursbureau, het psycho-technisch bureau, etc. De sterke groei van de staffunktie in het bedrijfsleven en van de externe „functional specialist" ${ }^{1}$ ) is dan ook inherent aan de dynamische, naoorlogse, economische ontwikkeling hier ten lande. In het algemeen kan men stellen dat hoe dynamischer het bedrijf of de bedrijfstak is, hoe meer er gebruik wordt gemaakt van de diensten van interne en externe hooggekwalificeerde krachten. ${ }^{2}$ )

Met de inschakeling van de computer ten behoeve van de bestuurlijke informatieverwerking is de behoefte voor de leiding aan bijstand op het bedrijfseconomische vlak sterk toegenomen. De ontwikkeling van nieuwe systemen, planmodellen, beslissingsregels e.d., die bij de toepassing van een computer ten behoeve van de bestuurlijke informatieverwerking noodzakelijk zijn, maakt een intern deskundige op deze gebieden tot een conditio sine qua non. Deze staffunktionaris is niet alleen door zijn kennis van deze materie onmisbaar, maar ook door zijn voortdurende aanwezigheid in het bedrijf, hetgeen een voorwaarde is voor de continuitteit van de automatiseringsprojekten. Een bedrijf dat automatiseert zal dan ook nooit alleen gebruik kunnen maken van externe adviseurs. Zonder de „,follow-up" van een interne deskundige zal elk automatiseringsprojekt tot mislukking zijn gedoemd.

Dit betekent echter niet, dat door de aanstelling van een interne organisatiedeskundige de diensten van een externe organisatie-adviseur overbodig zijn geworden. Er kunnen verschillende argumenten worden aangevoerd, die een voortgezette dienstverlening van een externe deskundige gewenst maken. ${ }^{3}$ )

In dit verband is het interessant even stil te staan bij de ontwikkeling van de organisatiebureaux in de laatste twee decennia. De aktiviteiten van deze bureaux hebben zich in deze periode steeds meer verbreed. Vaak begonnen als efficiencybureaux, d.w.z. gespecialiseerd in tijd- en bewegingsstudies ten behoeve van prestatiebeloningssystemen, hebben zij met de groei van de gebieden die tegenwoordig een rol in de bedrijfsvoering moeten spelen, hun dienstverlening aan bedrijfsleven en overheidsinstellingen eveneens vergroot. Brachten budgettering, marktanalyse,

\footnotetext{
1) De term is van J. M. Clark: Studies in the Economics of Overhead Costs (Chicago, Ill.: The University of Chicago Press, 1923), Dp. 120 e.v.

2) F. Harbison: "Utilization and Development of High-Talent Man Power"; The Technology Review, vol 60, no. 3 (Jan., 1958), pp. 3-4.

3) Drs. P. Verburg c.s.: "Organiseren en Organisatieonderzoek” (Leiden: H. E. Stenfert Kroese n.v., 1959), pp. 243-245.

Dr. P. G. Bosch: „De Betekenis van de Adviesfunctie voor de Leiding” (Leiden: H. E. Stenfert Kroese, 1962), pp. 31-38.
} 
korte termijnplanning en de toepassing van beheersingstechnieken, om slechts enkele gebieden op te noemen, de externe adviseur geleidelijk aan in de hogere strata van subalterne en hogere leiding, met adviezen die de besluitvorming ten behoeve van het te bepalen beleid beïnvloeden betrad hij het domein van de topleiding. Hiertoe behoren onder meer de adviezen betreffende lange termijnplanning, investeringskriteria, fusies en marktstrategie.

De grote bureaux die het gehele gamma van bovengenoemde aktiviteiten bestrijken, weten dan ook de relatie met hun cliënten te consolideren door intermitterend te fungeren als: „high-policy adviser, co-strategist, costcutter, reorganizer, hand holder, new business finder, hatched man (to chop out executive deadwood), and master of ceremonies". ${ }^{4}$ )

Deze groei van „functional specialist” tot „management consultant” heeft reeds enkele fundamentele vragen doen rijzen, waaraan wij hier voorbij willen gaan ${ }^{5}$ ). Van belang in deze ontwikkeling is echter, dat de externe organisatie-adviseur steeds meer de positie is gaan innemen van vertrouwensman en vraagbaak voor de topleiding, omdat van hem als ,neutrale buitenstaander" verwacht mag worden dat hij objektief en fris tegenover het bedrijfsgebeuren staat. Als zodanig blijft hij dus gehandhaafd naast de staffunktionaris op organisatorisch gebied.

\section{De relatie tussen externe en interne organisatiedeskundige}

Interne en externe deskundige staan met elkaar in funktionele relatie. In deze relatie brengt de staffunktionaris zijn intensieve kennis van het bedrijf in. $\mathrm{Hij}$ is in staat om niet alleen de scherpgetekende formele organisatie van het bedrijf te ontwaren, maar ook de daar doorheen schemerende slordige lijnen van de informele organisatie met zijn cliques en sankties, zijn eigen kommunikatiesysteem en zijn ongezalfde leiders. Deze kennis - vooral van belang bij de invoering van nieuwe projekten - de waardevolle interne kontakten en de voortdurende aanwezigheid van de staffunktionaris in het bedrijf zijn van groot nut voor de externe organisatie-adviseur. Menige goedopgezette reorganisatie mislukte doordat de organisatie-adviseur geen tegenspeler in het bedrijf had die de geaccepteerde voorstellen wist waar te maken door toe te zien op de uitvoering ervan en door gebruik te maken van zijn kontakten met en zijn invloed in de bedrijfsgemeenschap.

De externe deskundige brengt zijn buiten opgedane ervaring in, draagt over de nieuwe ontwikkelingen en technieken op bedrijfseconomisch gebied, boort informatiebronnen aan die voor de interne organisatiedeskundige juist door zijn bedrijfsgebondenheid moeilijk of niet toegankelijk zijn en snijdt die problemen bij de topleiding aan, die de interne organisatiedeskundige wegens zijn hierarchieke plaats in de organisatie niet kan oplossen of daar bij voorkeur van afziet. Hoewel van elke staffunktionaris uiteraard mag en moet worden geëist, dat hij de bedrijfsproblemen objektief benadert, kunnen zich situaties voordoen waarin de externe organisatie-adviseur als „objektieve buitenstaander" een doeltreffende rol kan spelen. Hiermede kan de interne organisatiedeskundige ook zijn voordeel doen door in dergelijke gevallen gebruik te maken van de diensten van zijn externe kollega.

Voor een vruchtbare samenwerking tussen de twee organisatie deskundigen is daarom de grootst mogelijke openheid en volledige wederzijdse informatie gewenst.

4) P. Stryker: „The Ambitions Consultants”; Fortune (May, 1954), pp. 83.

5) Stryker, loc.cit., pp. 83. 


\section{De „special representative”}

Het toenemend gebruik van ponskaartmachines in de administratie deed een nieuwe differentiatie ontstaan. Deze ontwikkeling tekende zich het eerst af in de verkoopstaf van de leverancier zelf, waar men al spoedig besefte dat kennis van de apparatuur alleen, niet voldoende was voor het voeren van een agressieve verkooppolitiek. De mogelijkheden van de apparatuur kregen voor de potentiële klant pas reliëf, als zij geprojekteerd werden tegen de achtergrond van een toepassing die voor het betreffende bedrijf van cruciaal belang was. De verkoper moest dus inzicht hebben in de problemen van het bedrijf en in de toepassingsmogelijkheden van de bedrijfsmachines. Daarnaast ontwikkelde zich ook zelfstandige differentiaties die zich toelegden op het adviseren van bedrijven die tot mechanisatie van hun administratie wensten over te gaan.

Met de komst van de computer wordt deze tendentie versterkt. Meer nog dan bij de konventionele ponskaartmachines doet zich hier de behoefte gevoelen van een fundamentele wijziging in verkoopmethoden. De gebruikelijke regionale indeling (branches) van de verkoopstaf en verkoopaktiviteiten blijkt steeds minder goed te voldoen. In plaats daarvan ontstaat geleidelijk een specialisatie naar bedrijfstak(ken), zoals: metaalverwerkende industrie, bankwezen, levensverzekeringsmaatschappijen, transportbedrijven, procesindustrieën, etc. De „special representative" doet hiermede zijn intrede, eerst in de Verenigde Staten, daarna naar het lijkt niet geheel van harte - ook in West-Europa.

Opmerkelijk is, dat ondanks het snel groeiende produktassortiment van de leverancier van informatieverwerkende machines geen openlijke produktspecialisatie bij de verkoopstaf optreedt. Van een aparte verkoopstaf voor computers en één voor konventionele administratiemachines is in de meeste gevallen geen sprake. De specialisatie voltrekt zich in de toepassing, niet in het assortiment.

De ,special representative” thans, heeft een kommerciële funk tie met een min of meer grondige kennis van het hele produktassortiment en van de toepassingmogelijkheden van deze apparatuur in een bepaalde bedrijfstak. De toekomst zal hierin waarschijnlijk een wijziging te zien geven die gaat in de richting van een specialisatie naar probleemgebieden, zoals: voorraad- en produktiebeheersing, transportproblemen, netwerkplanning bij grote projekten, etc. Gebieden dus, die over de bestaande indeling naar bedrijfstakken heengrijpen. Om een voorbeeld te noemen: in het z.g. „warehousing"-probleem, d.w.z. de problemen die zich voordoen bij voorraadketens is het niet van essentieel belang of men hier te maken heeft met een levensmiddelendistributiebedrijf met vele distributiepunten, dan wel met een elektrotechnisch produktiebedrijf met diverse gedecentraliseerde verkoopkantoren.

Hoe dan ook, de huidige „special representative” is een persoon, die een kommerciële funktie kombineert met die van „functioneel specialist”. Gezien dit laatste aspekt en mede doordat zijn gesprekspartner in vele bedrijven de interne organisatiedeskundige zal zijn, zal de „,special representative” in de meeste gevallen een academische of daaraan gelijkwaardige opleiding genoten hebben. $\mathrm{Zij}$ zijn de „top dogs" in de wereld van de bedrijfsmachinesleveranciers.

\section{De relatie tussen interne organisatiedeskundige en "special representative”}

De relatie tussen interne organisatiedeskundige en "special representative" is een fundamenteel andere dan die tussen interne en externe organisatiedeskundige. 
Dit fundamentele verschil spruit voort uit de gekombineerde funktie van de „special representative": hij is kommercieel-professioneel. Het kommerciële aspekt van deze funktie-met-een-verbindingsstreepje maakt hem ,verdacht" in de ogen van velen. Men meent, dat hij zijn kommerciële belangen altijd zal laten prevaleren boven de belangen van een klant. (En vergeet daarmede, dat in eigen bedrijf elke verkoper te horen krijgt dat hij de belangen van de klant boven die van het eigen bedrijf).

Dit „stigma” heeft tot gevolg, dat de rol van „objektieve buitenstaander” - die de externe organisatie-adviseur zo gaarne kultiveert - niet is weggelegd voor de „special representative”. Dit zou het professionele aspekt van zijn funktie kunnen ondermijnen, ware het niet dat hij het gemis van het predikaat "objektief" in de meeste gevallen handig weet op te vangen door zijn zakelijke relaties in zijn automatiseringsgesprek (acquisitie) te betrekken. In zijn kontakten met de interne organisatiedeskundige verwijst hij naar soortgelijke problematiek in andere bedrijven, biedt de staffunktionaris een introduktie aan in een bedrijf waar de oplossing van deze problemen werd gevonden met behulp van zijn informatieverwerkende apparatuur en laat het aan deze relatie over om aan zijn overtuigend betoog meer kracht bij te zetten.

Deze schrandere methode om een buitenstaander de doorslaggevende argumentering te laten fourneren is een beproefde en doeltreffende procedure, die niet kan worden nagevolgd door de externe organisatie-adviseur.

Het automatiseringsgesprek van ,special representative” en interne organisatiedeskundige vooronderstelt een zeker niveau bij deze laatste, d.w.z. kennis van, of in ieder geval, inzicht in de voorgestelde technieken. Het is uiteraard niet de taak van de „special representative” om bij gemis daarvan, voor kennisoverdracht zorg te dragen, hetgeen wel op de weg ligt van de externe organisatie-adviseur. Gebrek aan computerkennis kan de „special representative” echter opvangen door de staffunktionaris en zijn medewerkers een (leveranciers)kursus aan te bieden.

\section{De relatie tussen „special representative” en externe organisatie-adviseur}

De externe organisatie-adviseur is in de regel minder goed geïnformeerd omtrent de mogelijkheden en beperkingen van de informatieverwerkende apparatuur dan de ,special representative”. Uiteraard zijn op deze regel een aantal uitzonderingen op te noemen.

Ook wat betreft de kennis van de toepassingsgebieden en de daarin opgedane ervaring is de „special representative" de organisatie-adviseur meestal de baas. Het aantal externe organisatie-adviseurs dat daadwerkelijke ervaring heeft met computertoepassingen is nog steeds zeer gering. Slechts enkele grotere adviesbureaux hebben één of enkele deskundigen op het gebied van de administratieve automatisering. Maar zelfs deze deskundigen zijn niet zo frequent en zo veelzijdig betrokken bij computertoepassingen als de "special representatives" van goed ingevoerde computerleveranciers. Dit is het gevolg van het feit, dat nog te weinig organisatie-adviseurs met automatiseringsopdrachten bezig zijn, hetgeen niet verwonderlijk is als men bedenkt dat slechts een klein aantal adviesbureaux groot genoeg is om zich een automatiseringsdeskundige te kunnen veroorloven.

Hoe men de relatie ook bekijkt, er is altijd een zekere rivaliteit tussen externe organisatie-adviseur en "special representative". Beiden menen een automatise- 
ringsprojekt zonder de andere te kunnen realiseren. Indien de externe organisatieadviseur gespecialiseerd is op het gebied van de automatisering, zal hij geneigd zijn om alleen met de interne organisatiedeskundige - die voor hem onmisbaar is voor de realisering van het projekt - de hoofdlijnen van het automatiseringsprojekt uit te werken en de bijdrage van de „special representative” te beperken tot verstrekken van de voor dit projekt benodigde machinespecificatie. In zulk een passieve rol wordt de ,special representative” teruggebracht tot enkel verkoper, zonder zijn professionele deskundigheid aan het projekt te kunnen bijdragen. Een bepaald onbevredigende rol indien men voor ogen houdt, dat de ,special representative" belang heeft bij een suksesvolle inschakeling van zijn apparatuur, zowel uit kommercieel als uit professioneel oogpunt.

Is de externe organisatie-adviseur niet of minder deskundig op automatiseringsgebied, dan zal hij geneigd zijn om zich terug te trekken in een rol van kritische beoordelaar van een ingediend automatiseringsontwerp, d.w.z. hij zal van de „special representative” een volledig uitgewerkt plan de campagne verwachten, om dit ontwerp dan - eventueel gezamenlijk met de interne organisatiedeskundige - kritisch te bestuderen. Uiteraard zal hij meerdere computerleveranciers op het projekt laten ,inschrijven".

Deze al dan niet manifeste rivaliteit tussen externe organisatie-adviseur en „special representative" is het gevolg van het in elkaar vloeien van het werkterrein van de één in de ander en van de tegenstelling kommercieel-professioneel.

\section{Een driehoeksverhouding}

De hierboven met opzet sterk aangezette tegenstellingen in de onderlinge verhouding van de drie hoofdfiguren van een automatiseringsprojekt, kunnen een negatieve rol spelen bij de uitwerking en uitvoering ervan. Zonder deze polariteiten onnodig te overtrekken moet zulk een belangentegenstelling toch als schadelijk voor elk automatiseringsprojekt worden gekenmerkt. Een doelmatige samenwerking zou hierin uitkomst kunnen brengen, vooropgesteld dat elk van de drie gesprekspartners een open oog heeft voor de bijdrage van de anderen. Een positieve houding ten opzichte van elkaar is dus een vereiste. Een taakverdeling tussen de drie deskundigen zou er als volgt kunnen uitzien:

- Indien een bedrijf nog niet automatiseringsbewust - maar wel automatiseringsrijp - is, ligt hier een taak zowel voor de externe organisatie-adviseur als voor een „special representative”. Het bewustwordingsproces is in feite het interesseren van de topleiding voor de mogelijkheden van een computer ten behoeve van de bestuurlijke informatieverwerking. Dit overtuigings(overredings)proces kan het meest effek tief geschieden door „derden”, waarbij vooral de externe organisatieadviseur een belangrijke rol kan spelen. Is de externe adviseur echter niet deskundig op het gebied van de administratieve automatisering, dan zal deze taak opgenomen moeten worden door „special representative” en interne organisatiedeskundige.

De „special representative” zal de bijstand van de staffunktionaris niet kunnen missen, omdat hij minder makkelijk toegang tot de topleiding heeft dan de externe organisatie-adviseur. Hij zal dus eerst de staffunktionaris van de noodzaak tot automatisering moeten overtuigen, die daarna de topleiding hierover kan benaderen via een voorstel tot systeemverbetering. De overdracht van ken- 
nis omtrent de automatiseringsapparatuur en zijn mogelijkheden aan de interne organisatiedeskundige, ligt op de weg van de „special representative”; de hiermede nauw samenhangende kennis van „business control”-technieken zal door de externe organisatie-adviseur overgebracht moeten worden, zo daaraan behoefte is. Wij zien hier dus reeds een samenwerkingspatroon ontstaan.

- De „special representative” kan daarna, bijgestaan door enkele kollega's, een voorlichtingsdag in het bedrijf ten behoeve van de topleiding organiseren, waarin de mogelijkheden van de computer geëtaleerd en de relevante toepassingsgebieden belicht worden. (Zijn er meerdere computerleveranciers in het spel dan zou de directie kunnen overwegen of het niet doelmatiger zou zijn om een voorlichtingskonferentie van de Stichting Studiecentrum voor Administratieve Automatisering bij te wonen). De externe organisatie-adviseur zou hierna in kunnen gaan op de beheersingstechnieken die aan de meeste geavanceerde computertoepassingen ten grondslag liggen.

- Heeft de topleiding de indruk gekregen, dat de inschakeling van een computer in het administratieve proces een voordeel voor het bedrijf zou kunnen zijn, dan zal een opdracht volgen tot het instellen van een vooronderzoek. Dit globale onderzoek moet gericht zijn op een duidelijke probleemstelling, een definiëring van de behoef te tot systeemverbetering, de mogelijke aanwending van een computer ter realisatie hiervan, de hiervoor noodzakelijke voorwaarden en het gewenste effekt van de automatisering op het bedrijfsgebeuren.

De topleiding kan dit onderzoek uiteraard aan de externe organisatieadviseur opdragen, of aan een organisatiebureau dat zich heeft gespecialiseerd op het gebied van de elektronische informatieverwerking. Dit laatste treft men veel in de Verenigde Staten aan. Onzes inziens is het echter doelmatiger om het vooronderzoek te laten verrichten door een team uit het bedrijf onder leiding van de interne organisatiedeskundige. Bij dit vooronderzoek is het nodig zowel externe organisatie-adviseur als „,special representative” te betrekken, om te voorkomen dat reeds bij de probleemstelling te veel van één oplossingsmogelijkheid wordt uitgegaan. Men trekt tijdens dit vooronderzoek dan het volle profijt van de elders opgedane ervaringen van de twee externe deskundigen.

De eindrapportering aan de topleiding dient snel tot stand te komen: zoveel mogelijk binnen de termijn van drie tot zes maanden. In het rapport wordt ook een door de ,special representative" opgestelde machinespecificatie opgenomen.

- Besluit de topleiding over te gaan tot inschakeling van een computer ten behoeve van de bestuurlijke informatieverwerking, dan worden de volgende fasen van de voorbereiding beheerst door de aktiviteiten van stuurgroep en werkgroep.

In de stuurgroep zal de interne organisatiedeskundige als rapporteur zitting hebben, terwijl ook de externe organisatie-adviseur aan de besprekingen deelneemt. Ad hoc kan ook de „special representative” worden uitgenodigd om een bespreking bij te wonen.

In de werkgroep berust de leiding bij de interne organisatiedeskundige. Deze zal zich bij de voorbereidingswerkzaamheden ten behoeve van de installatie van de computer door de ,special representative" laten bijstaan. In dit stadium - de computerkeuze is reeds gevallen - is zijn kommercieel stigma verdwenen voor het automatiserend bedrijf en de „special representative” kan door zijn ervaring in dergelijke situaties waardevolle bijdragen leveren aan de voorbereidingen. $\mathrm{Hij}$ 
kan de werkgroep behoeden voor de gebruikelijke fouten, de voortgang van de voorbereidingen zoveel mogelijk trachten af te stemmen op de leverdatum van de computer en zo nodig vertragingen aan de stuurgroep rapporteren.

Deze bijstand van de ,special representative" - een bijstand die voor het bedrijf geen extra kosten met zich brengt - toont het belang dat de computerleverancier heeft bij een suksesvolle computertoepassing, waarmede de relatie tussen klant en leverancier tot een kontinue is geworden. Ten voordele van beiden! Want niet alleen blijft de klant op de hoogte van de nieuwste ontwikkelingen op het gebied van "hardware” en ,software”, ook de „special representative” verrijkt zijn kennis met een meer dan incidentele ervaring in het automatiserende bedrijf.

- Heeft een bedrijf reeds een computer, doch wenst de interne organisatiedeskundige tot vervanging van de bestaande configuratie over te gaan, dan zullen zowel externe organisatie-adviseur als „special representative” met een passievere rol genoegen moeten nemen. Door zijn dagelijkse ervaring met de mogelijkheden en beperkingen van de apparatuur en met de problematiek van de inschakeling van een computer in de bestuurlijke informatieverwerking zal de staffunktionaris in de regel precies weten wat hij nodig heeft, hoe hij de voorbereiding moet aanpakken en welke problemen hij zal moeten oplossen. In het kort, de interne organisatiedeskundige zal in deze situatie geneigd zijn om zoveel mogelijk een ,one-man show" op te voeren.

Vanuit dit superioriteitsgevoel zal hij zelfstandig zijn keus willen maken, hetgeen hem vaak verleidt tot het maken van ingewikkelde snelheids- en kostenberekeningen. De ,special representative” is dan nog alleen maar informateur, die de gegevens omtrent de nieuwste ontwikkelingen op het gebied van „hardware" en ,software" verstrekt.

De externe organisatie-adviseur zou door de topleiding wederom ingeschakeld kunnen worden om een advies uit te brengen over de voor het bedrijf meest geeigende configuratie. De interne organisatiedeskundige is misschien in de ogen van de topleiding te veel hogepriester van de computerafdeling geworden en zijn voorstellen zullen dan suspekt zijn. Toch zal de externe adviseur in zulke situaties er goed aan doen om zijn eigen konklusies door te nemen met de interne deskundige, want zijn computerkennis zal veelal minder zijn dan die van zijn interne kollega. Een gemeenschappelijk standpunt in de computerkeuze zal daarom regel zijn.

\section{Slotopmerkingen}

In dit artikel hebben wij getracht een aarzelend begin te maken met de analyse van een steeds meer voorkomende "driehoeksverhouding” tussen externe organisatie-adviseur, interne organisatiedeskundige en ,special representative" van een computerleverancier. In onze funktie van intern organisatiedeskundige in een bedrijf dat een computer heeft ingeschakeld ten behoeve van de bestuurlijke informatieverwerking, hebben wij in de afgelopen jaren veelvuldig kontakt gehad zowel met de organisatie-adviseur als met de „special representative”. Door deze kontakten hebben wij ons gaandeweg een beeld gevormd van de funktionele verhoudingen zoals die zouden moeten zijn. Dit beeld hebben wij geretoucheerd met de opmerkingen verkregen uit gesprekken met verschillende organisatie-adviseurs, „special representatives” en kollega's in andere bedrijven. 
Het doel dat met dit artikel beoogd wordt, is het schetsen van een doelmatige taakverdeling, een samenwerkingspatroon. Uiteraard pretenderen wij niet de ideale oplossing gevonden te hebben. Elke oplossing is afhankelijk van de interne en externe verhoudingen en van de persoonlijkheden van de drie hoofdrolspelers in het automatiseringsspel. Indien dit artikel echter als uitgangspunt kan dienen voor een diskussie over deze voor het automatiserende bedrijf zo belangrijke „driehoeksverhouding", heeft het aan zijn doel beantwoord. 